\title{
Introducción. El suicidio en la literatura, el cine y el arte visual en España e Hispanoamérica
}

Es sabido que alrededor de los años sesenta del siglo pasado prominentes estudiosos de la literatura y la filosofía decretaron "la muerte del autor". Haciendo frente a la voz autorial en la obra literaria, Roland Barthes desmanteló la autoridad del escritor al afirmar que "la escritura es la destrucción de toda voz, de todo origen. La escritura es ese lugar neutro, compuesto, oblicuo, al que van a parar nuestro sujeto, el blanco-y-negro en donde acaba de perderse toda identidad, comenzando por la propia identidad del cuerpo que escribe" (65). El académico francés subrayaba así la superación del privilegio otorgado al autor por el historicismo tradicional: en lugar de asumir al autor como fuente única del discurso, el análisis debía dirigirse hacia el lenguaje literario y la mentalidad literaria colectiva (Lentricchia 136). Desde esta visión, disminuía para el análisis textual la validez de la persona del autor como originadora única del significado. Aunque tal paradigma no abolía al autor real, es evidente que su rol quedaba visiblemente reducido. ${ }^{\mathrm{T}}$

Subrayando el papel de la crítica estructuralista, Gerald Graff señalaba que "the concept of literary autonomy has come under fire recently from structural criticism, which attempts to desmistify literature by showing that literary language, linguistic conventions, and 'textuality,' not the imagination or consciousness of the writer, are the constitutive agents of writing" (I8). El post-estructuralismo dio forma a una serie de propuestas basadas en una lectura inmanente, centrada en los textos mismos. La obra literaria, consistente de lenguaje, se analizaba decodificando una obra contemplada como un todo, las relaciones diferenciales entre sus elementos y la inmanencia de su estructura (Iser, "The Current Situation" 7). $\mathrm{Y}$ aun cuando estas lecturas probaron su utilidad y contribuyeron a redefinir los roles de la literatura, particularmente con referencia al ahondamiento en las funciones del texto literario que se evidenciaban en las estructuras mismas, también es cierto que ciertos críticos enfatizaron la relevancia del lector y su contexto. Por ejemplo, Hans Robert Jauss afirmó su rechazo a "la panacea de las perfectas taxonomías, de los cerrados sistemas de signos y de los formalizados modelos de la descripción" (6o) para sugerir una teoría literaria inclusiva de la historia, 
en su vinculación con las instancias de producción y recepción; es decir, la dinámica entre las instancias autorial, del lector y la obra (60). Jauss se abocó a fortalecer al lector como instancia válida y relevante en la práctica interpretativa, considerando que "la literatura y el arte sólo se convierten en proceso histórico concreto cuando interviene la experiencia de los que reciben, disfrutan y juzgan las obras" (59). Por otro lado, y desde una perspectiva distinta que también subrayaba la función del receptor de la obra, el italiano Umberto Eco propugnó que el texto no se definía por la intención autorial o en la producción, sino por la necesidad de una inoculación de sentido por parte de su destinatario: "un texto quiere que alguien lo ayude a funcionar" (Lector in Fábula 76). Su noción de "obra abierta", que fortalecía el papel del intérprete, es ampliamente conocida e involucra activamente al "usuario":

... el autor produce una forma conclusa en sí misma con el deseo de que tal forma sea comprendida y disfrutada como él la ha producido; no obstante, en el acto de reacción a la trama de los estímulos y de comprensión de su relación, cada usuario tiene una concreta situación existencial, una sensibilidad particularmente condicionada, determinada cultura, gustos, propensiones, prejuicios, personajes, de modo que la comprensión de la forma originaria se lleva a cabo según determinada perspectiva individual." (Eco, Obra abierta 65)

Es evidente que la propuesta de Eco enfatizaba la figura del receptor. Es decir, aunque el autor se asumía como el sujeto organizador de los elementos comunicativos con una determinada finalidad, la interpretación, desde esta visión, se deslizaba hacia el terreno de la dialéctica producida entre la obra y su intérprete. Se expresaba así la apertura de un abanico de posibles análisis y lecturas, asentado en la pluralidad de receptores. Esta posición no carecía de sustento puesto que, como bien lo menciona Michael Glowinski, el intérprete no es una tabula rasa; llega al texto con un cierto número de creencias y hábitos (76). En una historia de la literatura que había evidenciado "preocupación por el autor (romanticismo y siglo XIX); interés por el texto, excluyendo todo lo demás (Nueva Crítica); ... cambio de enfoque, dirigido al lector" (Eagleton 95), la inclusión de este último parecía completar la cadena interpretativa con el eslabón faltante, ya que los "procesos de significación sólo pueden materializarse mediante la lectura" (95). En el campo específico de la literatura, los planteamientos que descubrían la relevancia del rol del lector y su experiencia en relación a la obra, hasta ese momento no enfatizada por la ciencia literaria, no podían sino resquebrajar la monolítica visión historicista del autor como instancia que dotaba de sentido a la obra. "¿Qué importa quién habla?", se 
preguntaba Michel Foucault, tomando palabras de Beckett (7). El recorrido histórico de la función del hombre-autor realizado por el filósofo francés subrayaba la pertenencia de la obra a la cultura. En medio de este amplio espectro de propuestas (las mencionadas son una pequeña muestra), hay que señalar que el ensombrecimiento de la figura del autor sirvió de incentivo para otros planteamientos en relación a un significado que involucrara todas las instancias. Por ejemplo, en su primer capítulo de Validity in Interpretation dedicado a la defensa del autor, E.D. Hirsch hacía referencia a las personas participantes en el proceso interpretativo: "meaning is an affair of consciousness and not of physical signs or things. Consciousness is, in turn, an affair of persons, and in textual interpretation the persons involved are an author and a reader" (23).

Ahondando más detenidamente en la importancia de la discusión, se aprecia que tanto en el contexto antes señalado de la lectura inmanente como en la propuesta del rol preponderante del lector, la obra de los escritores suicidas llama poderosamente la atención, ya que pone en entredicho la posibilidad de prescindencia de la figura del autor en el acto interpretativo. Aunque, y sobre todo desde los desarrollos de la teoría de la recepción, se reconoce que el lector juega un rol primordial en el proceso de interpretación, cuando se trata de textos producidos por suicidas, una tentación inmediata, casi imperativa, es la de involucrar a la instancia autorial. Se produce una variación de la lectura cuando se enfrenta el texto de un escritor cuya muerte constituyó un acto auto-infligido, puesto que resulta inevitable que el pensamiento se dirija a la persona del autor $y$, particularmente, a una interrogación sobre sus angustias, su modo de vida y los posibles motivos que lo llevaron a la decisión de eliminarse. ${ }^{2}$ Con un sentimiento en cierto modo afín al de Exécrates interrogando a Fedón, el lector intenta extraer de la obra detalles sobre las circunstancias que rodearon los últimos momentos del autor. Emprende así una búsqueda singular, que le permita descubrir en la obra literaria trazas de una inquietud, angustia o estado mental capaz de conducir a la clausura voluntaria de la vida. El suicidio irrumpe e interpela la lectura inmanente, tornando la muerte por mano propia elemento imprescindible en el intento de conocer los posibles significados del texto. El gesto suicida termina así reviviendo a ese escritor defenestrado por "la muerte del autor", reasignándole un lugar como instancia válida en el proceso de interpretación.

A partir de la pluralidad de las propuestas interpretativas mencionadas más arriba, parece acertado considerar el suicidio en su asociación con el autor como generador de la obra y también en sus vínculos con el lector, en tanto la obra se activa a partir de la mirada de 
este último, proceso que incluye las ideas que existen en el imaginario correspondiente al contexto de recepción. Autor y lector forman así parte de una dinámica interpretativa que conecta la obra con el mundo, según señala Iser:

la obra literaria tiene dos polos, que podríamos llamar el artístico y el estético: el artístico se refiere al texto creado por el autor, y el estético a la concretización llevada a cabo por el lector. A partir de esta polaridad se deduce que la obra literaria no puede ser completamente idéntica al texto, sino que debe situarse a medio camino entre los dos. La obra es más que el texto, puesto que el texto toma vida solo cuando es concretizado. ("El proceso de lectura" 215)

La apreciación de los contextos de creación y recepción redefine la misión del crítico al vincular la obra con su realidad extra-textual. Dentro de esta amplia mirada, en relación al tema que nos atañe, son importantes los valores que se asignan al suicidio en distintos tiempos y espacios, que se concretizan y activan en la lectura. Es evidente que el suicidio incomprensible enigma para muchos - enfrenta al lector con el delgado hilo del que pende la vida frente al deseo de muerte, y debido a ello los textos en los que hipotéticamente podrían hallarse las huellas de esa macabra oscilación han ejercido fascinación tanto sobre lectores como sobre críticos literarios. En el caso de autores que terminan con sus vidas, inevitablemente, el conocimiento de la figura del finado, sus rasgos psicológicos, sus circunstancias de vida y muerte, se entremezclan con las palabras de un texto en el que se pretende encontrar las respuestas a dudas e interrogantes que surgen sobre un tema tan complejo como la muerte por mano propia.

Desde un punto de vista socio-histórico, es importante notar que la reflexión sobre el suicidio por parte de las sociedades occidentales ha variado significativamente a lo largo del tiempo. El suicidio es un acto que se ha practicado durante miles de años y, por cierto, no siempre ha sido juzgado de forma negativa. Es sabido que en Grecia y Roma el suicidio gozaba de aprobación si se relacionaba con la defensa del honor; debido a ello la historia de los griegos y los romanos está plagada de suicidios que tenían como fin evitar la captura, la humillación o la muerte (Rosen 5). El cristianismo temprano tampoco ejerció una censura marcada hacia la clausura voluntaria de la vida, ya que fue recién el siglo V que San Agustín realizó una interpretación - considerada arbitraria por muchos - que incluía el suicidio en el Sexto Mandamiento ("No matarás") (Brandt 65). Tras la legislación dada por la Iglesia en el siglo VI, el suicidio se transformó en un grave pecado (Alvarez, The Savage God 5I), y durante 
siglos, las sociedades cristianas condenaron el suicidio. ${ }^{3}$ En esta censura quedaban incluidos tanto los suicidas que fallaban en su intento como aquellos que lograban su propósito, destinando a los primeros a una muerte a la que ellos mismos ya se habían condenado y a los segundos a la degradación del cuerpo.4 Hay que señalar que, en el medio de estas sociedades agudamente críticas de la muerte por mano propia, filósofos como Erasmo de Rotterdam y Michel de Montaigne, entre otros, se pronunciaron a favor de esta. Asimismo, en el siglo XVIII el filósofo David Hume, en su defensa del suicidio como acto legítimo, explicaba que eran las leyes generales de la materia y del movimiento de las que dependía la vida humana. Puesto que Dios había establecido dichas leyes, su modificación o alteración no implicaba ninguna transgresión, porque procedía de los poderes dados por Dios a sus criaturas (4-5). Hume implicaba que tampoco el suicidio comportaba una verdadera transgresión, al preguntarse: "Shall we assert that the Almighty has reserved to himself in any peculiar manner the disposal of the lives of men, and has not submitted that event in common with others, to the general laws by which the universe is governed?" (6). Ciertamente el filósofo respondía a la concepción del suicidio como crimen religioso, ejercido directamente contra los designios de Dios.

George Rosen relata que en el siglo XVIII las ideas sobre la influencia del medio ambiente se asociaron al acto del suicidio, que comenzó a contemplarse como producto de "una melancolía". Se empezó entonces a delinear con claridad una visión del suicidio asociada a la enfermedad mental (25).5 Un cambio crucial en la perspectiva de las sociedades opera a partir de la publicación del conocido estudio de Emile Durkheim, quien en el siglo XIX sistematizó la teoría más relevante sobre la muerte por mano propia. Durkheim planteó la posibilidad de la consideración de la muerte auto-infligida ya no como acto únicamente imputable al individuo, sino como un caso social: "we know their connection with the most ineradicable element in the constitution of societies, since they express the mood of societies, and since the mood of peoples, like that of individuals, reflects the state of the most fundamental part of the organism" (369). Esta mirada, que alcanzaba al conjunto de la sociedad, neutralizaba parcialmente la visión del suicidio como un acto execrable y punible, según afirma A. Alvarez en The Savage God: "The broad effect of Durkheim's masterpiece was to insist that suicide was not an irredeemable moral crime but a fact of society" (93). Aunque el estudio de Durkheim ha recibido distintos cuestionamientos, se reconoce su influencia en la evolución de las ideas sobre el suicidio, ya que la atención pasó a centrarse ya no en la culpa achacada al acto mismo, sino en la sociedad y en los 
factores sociales que se encontraban en su base. Lo que se consideraba un acto criminal pasaba a ser, como lo sugiere Alvarez, un acto que, si bien ya no era tan duramente condenado, todavía conllevaba un estigma: "a dirty little secret" (The Savage God 79). Por otro lado, ya en el siglo XX, surgieron nuevos planteamientos en torno a la auto-destrucción. Mientras para algunos, como Erwin Stengel, el suicidio significaba un grito de auxilio (Alvarez, The Savage God 8I), para otros representaba una solución a lo absurdo de la existencia (Camus io8). Es bien sabido que en su célebre $E l$ mito de Sísifo Albert Camus proponía que juzgar si valía la pena vivir equivalía a contestar la pregunta más importante de la filosofía (IO7). Ahora bien, en el contexto clínico, los múltiples estudios sobre el suicidio en las áreas de la psicología y psiquiatría sugieren una marcada asociación del suicidio con la enfermedad. Y hay que reconocer que, al menos en parte, estas visiones (estigma y enfermedad) han permanecido vigentes hasta tiempos muy recientes.

Dentro de las muchas ideas que se han debatido y debaten en torno al suicidio, destaca el examen de las relaciones que se tejen entre suicidio y creatividad, plausibles de ser conectadas con las obras literarias, fílmicas y plásticas. Alvarez ha mencionado que la mezcla de genio y melancolía, que preocupaba en el Renacimiento, es transformada por los románticos al combinar genio y muerte prematura ("Literature" 33), acercándose a una vinculación entre el espíritu creador y una muerte súbita o violenta. Y en efecto, se ha llegado a afirmar que el porcentaje de intentos de suicidio sería significativamente mayor entre los escritores, particularmente los poetas (Runco 639). En este sentido, la creatividad literaria, en especial la que conduce a la creación poética, aparece como fuente de un dolor que hipotéticamente podría conducir al suicidio. La siguiente declaración de la poeta argentina Alejandra Pizarnik, quien se suicidó en 1972, resume este sentimiento: "En el fondo yo odio la poesía. Es para mí una condena a la abstracción. Y además, me recuerda esa condena ... me recuerda que no puedo hincar el diente en lo concreto" (27I). Si bien Pizarnik distingue claramente el origen de su dolor - de fuente a la vez social y literaria - y se ubica en el espacio de la inadaptación, la idea de transgresión asociada a la enajenación, comúnmente relacionada con la creación artística e imputada a los artistas, resuena en los vínculos que se tejen entre escritores y suicidio.

En la contemplación del suicidio ya no como acción del autor sino como tópico literario, se asume que la literatura - así como el cine - desde su estatus pseudo-ficcional, resulta un medio ideal para la representación de este acto final, dado el alto grado de estigma que este conlleva. El tema del suicidio en la literatura ha sido profusamente examinado, como motivo 
de narrativas y poéticas que representan muertes auto-infligidas por diversos personajes. Desde Shakespeare hasta Goethe, muchos textos han relatado suicidios cometidos por sus personajes en distintos escenarios. En este sentido, las ideas sobre el suicidio que se originan en los diversos contextos - autorial, de la obra, de la recepción - son relevantes para la interpretación de las narrativas que relatan este tipo de muerte.

Gran parte de los estudios sobre suicidio y escritura se han llevado a cabo en relación a la literatura anglo-norteamericana - como lo prueban los numerosos ensayos sobre Ernest Hemingway, Sylvia Platt y Virginia Woolf, entre otros -, haciendo evidente un vacío en el análisis de este tema en el ámbito hispánico. Los artículos incluidos en este número monográfico intentan llenar este espacio de trabajo crítico, al analizar el suicidio no solo en la literatura, sino también en el cine y la creación gráfica. Este volumen reúne ensayos sobre el tema del suicidio en las representaciones textuales, fílmicas $y$ visuales de España $e$ Hispanoamérica, que siguen ciertas líneas interpretativas generales: algunos artículos analizan suicidios llevados a cabo por personajes de ficción y sus significaciones psicológicas, históricas, sociales y/o políticas, tomando en cuenta los contextos específicos de las obras, mientras que otros exploran el tema del suicidio de los autores de obras literarias desde la perspectiva de la recepción crítica, examinando las connotaciones que emanan de la imagen del suicida recreada a partir de los textos. Finalmente, algunos ensayos iluminan aspectos hermenéuticos inherentes al examen del tópico del suicidio en determinadas obras visuales, así como de la literatura y el cine.

Los artículos que presentamos analizan diversos vínculos entre suicidio y creación, y abordan textos o material fílmico/visual desde una variedad de ópticas: además de las vinculadas específicamente a los estudios sobre literatura y cine, de género, sociológicas, políticas, filosóficas, psicológicas. Los ensayos, que describimos brevemente a continuación, han sido organizados tomando en cuenta la cronología de las obras que son objeto de estudio:

En "Ángel Ganivet (I865-I898) ante la crítica. El suicidio del escritor como negación de la 'muerte del autor', Luis Álvarez Castro hace un recorrido de la recepción crítica del suicidio del escritor español Ángel Gavinet, problematizando la idea de "la muerte del autor" propugnada por Roland Barthes. Desde una perspectiva hermenéutica, Álvarez Castro postula que el fin voluntario de la existencia de Gavinet afecta la mirada hacia su trayectoria y trabajo literario, dando como resultado que este último pueda ser interpretado como una nota suicida. El axioma de la Nueva Crítica que propone la prescindencia del autor quedaría así 
debilitado ante el reto que significa la introducción de su muerte voluntaria como elemento de análisis. La figura del suicida representa una crisis de la teoría crítica, ya que permite la recuperación del papel central del autor en el proceso interpretativo. Álvarez Castro incide en la importancia que adquiere Gavinet a partir de su acto final: el suicidio del escritor deviene en la imposibilidad de la muerte del autor.

El ensayo "Death as Volition: Suicide in the Early Azorín" de David Wood explora la inclusión del suicidio en la obra del escritor español José Martínez Ruiz, conocido como Azorín. Wood examina instancias de suicidio en los trabajos tempranos de este autor (Bohemia, Diario de un enfermo), constrastándolas con la aparición de este tema en obras tardías como La voluntad, publicada en I9O2. Aunque la muerte es un tema recurrente en la narrativa de Azorín, su representación evoluciona a lo largo de su obra. Wood argumenta que los sujetos ficcionales responden positivamente a sus contextos espaciales y temporales; sin embargo, en relación a la muerte, el suicidio se convierte en un acto imposible en los últimos trabajos de Azorín, debido a que requiere una determinación que sus personajes no poseen. El artículo destaca la relación entre el entorno y el acto suicida; para ello, las ideas de Durkheim permiten plantear que las muertes voluntarias narradas por Azorín constituyen actos determinados por las relaciones sociales de sus sujetos. Asimismo, Wood repara en el tratamiento del lenguaje por el autor español, y en la manera en que el acto de escritura se convierte, en la obra de Azorín, en un dilema entre la vida y la muerte.

"Más allá de la necrografía: una relectura del suicidio en la vida y obra de Horacio Quiroga" (1879-1937) de Carlos Abreu Mendoza propone una indagación en el mito de Horacio Quiroga como autor marcado por la muerte. Abreu argumenta que la fijación en los episodios trágicos que marcaron su existencia y suicidio ha hecho que la biografía de Quiroga adquiera los rasgos fúnebres de una necrografía, constituyéndose el suicidio en el elemento organizador del relato de su vida. Su primer propósito es deconstruir la manera en que esta necrografía se constituye a partir de la muerte por mano propia como necesario epílogo a la macabra historia del escritor. El segundo es cuestionar esta imagen desde el corpus que forman sus textos. Según Abreu, la escritura de Quiroga, aunque incluye reiteradamente la muerte, no deja claves que conduzcan al suicidio ni referencias directas a las tragedias ocurridas en su vida. Es en este sentido, el del contraste entre la insistencia biográfica en el acto suicida y el silencio que sobre este tema puede hallarse en la escritura, que Abreu propone deconstruir y problematizar el mito sobre Quiroga, a partir de un examen de su obra y de los textos críticos que han contribuido al mito: 
Vida y obra de Horacio Quiroga (r939) de José María Delgado y Alberto J. Brignole, El hombre y la obra de Pedro Orgambide (1954), El hermano Quiroga. Cartas de Quiroga a Martínez Estrada de Ezequiel Martínez Estrada (1957) y El desterrado. Vida y obra de Horacio Quiroga de Emir Rodríguez Monegal (1968). A partir de esta lectura, el ensayo plantea abrir paso a una figura de autor más maleable y compleja con la que superar la ilusión retórica a la que, según Pierre Bourdieu, sacrificamos toda historia de vida como relato coherente.

"Lecturas visuales de 'De suicidios' de Max Aub" (1903-1972) de Rosa Sarabia lleva la reflexión sobre el tema del suicidio al género de la representación gráfica o visual. Sarabia analiza las ilustraciones creadas en base a la obra "De suicidios" de Max Aub, escritor, artista plástico y guionista de cine. Con este título, el autor publicó treinta y ocho relatos de sus relatos breves en la Revista de la Universidad de México a partir de i96I, que fueron después incluidos en las sucesivas ediciones de Crímenes ejemplares. Varios de estos microrrelatos, que en su mayor parte no contienen un juicio moralizante sobre el suicidio, fueron ilustrados y llevados a la historieta por prominentes artistas. De acuerdo a la autora, algunas de estas "lecturas visuales" destacan lo absurdo y metafórico del lenguaje de los "suicidios" aubianos, mientras que otras añaden nuevos significados a los relatos condensados. Asimismo, se enfatiza la función desacralizadora, lúdica y subversiva de la risa que sobre la muerte mantienen estas representaciones. Sarabia recorre analíticamente las ilustraciones de Liniers, Santiago Sequeiros y Frank Arbelo, para lo que recurre a las ideas sobre microficción de Domingo Ródenas de Moya, a las de Julia Kristeva sobre la otredad, así como a los planteamientos de Nietszche sobre la dimensión metafórica del lenguaje. Sarabia repara también en la inserción de la iconografía mexicana, particularmente en el trabajo de Liniers, que estaría relacionada tanto con la experiencia vital de Aub en México como con la cosmovisión náhualt sobre la muerte. La autora propone que las ilustraciones sobre los suicidios dialogan con los textos aubianos y constituyen lecturas de aquello que la hiperbrevedad oculta. Visualizan lo no dicho, y al hacerlo, expanden y manipulan las posibilidades significativas de los mismos, constituyendo obras autónomas y de valor artístico propio.

María Teresa Grillo, en su artículo "El suicidio como performance en la obra póstuma de José María Arguedas" analiza El zorro de arriba y el zorro de abajo (1969), la novela del autor indigenista peruano publicada póstumamente, así como los diarios que escribió de manera simultánea a esta obra. Aunque muy conocido, Arguedas fue un escritor criticado en relación a la autenticidad de sus representaciones de la realidad andina. 
Grillo plantea que la escritura simultánea de los diarios y la novela produce un juego intertextual en el que el suicidio, visto como una performance, se proyecta sobre la obra ficcional, dotándola de una validez a través de la cual el autor refuerza póstumamente su identificación con lo andino. Tomando en cuenta los postulados de Ute Berns sobre performance y narratividad, el artículo propone que la novela contiene en sí misma varios niveles de performance, que emanan de su polifonía y de la cosmovisión andina desde la que se enuncia, en los que se articulan el suicidio y la muerte.

"Perder y ganar suicidios: teorías vilamatasianas del espacio literario" de Catalina Quesada Gómez, analiza la propuesta literaria de Enrique VilaMatas en Suicidios ejemplares (199r). Quesada Gómez examina en este artículo las complejas relaciones entre suicidio, silencio y escritura. Al margen de las interpretaciones en clave existencialista, sociológica o antropológica sobre la obra, aborda los textos de Vila-Matas, basándose en las ideas expuestas por Emilio Lledó en El silencio de la escritura: si la escritura es una forma de atestiguar la vida, la falta de esta correspondería a la anulación del ser. En este sentido, la autora propone que Suicidios ejemplares, además de explorar la senda del exterminio de la escritura y su equiparación con el acto suicida, pone en escena las ideas vilatmasianas sobre la espacialidad de esta. La obra introduce una suerte de teoría literaria a partir del motivo del suicidio, que reclama la importancia de lo espacial en la literatura. La poética del espacio que puede leerse en la narrativa de Vila-Matas sugiere, asimismo, la necesidad de que la literatura, desprovista del fluir del tiempo asociado al discurso, se aproxime a la ucronía propia de las artes plásticas.

"Gendering the Suicidal Body: Male Translation of Female Death in Javier Marías' Corazón tan blanco (1992)”, escrito por Heather Jerónimo, se centra en el análisis del protagonista semi-autobiográfico, Juan, de la novela de Javier Marías, y la exploración de su identidad a través del examen del pasado de su padre, dos de cuyas esposas fallecieron en circunstancias que incluyen secretos y suicidio. La muerte auto-infligida de las mujeres en Corazón tan blanco facilitaría la vida y la longevidad de los hombres, especialmente de Juan, cuya existencia hubiera sido imposible sin las muertes de las primeras dos esposas de su padre. En la novela el suicidio se revela como una herramienta que conecta el cuerpo femenino al sufrimiento violento, a la vez que sirve como experiencia liberadora para la validación de la identidad masculina. Basándose en el trabajo de Elizabeth Grosz, quien plantea el cuerpo como un producto cultural, un recinto abierto a la inscripción de diversos mensajes, Jerónimo sugiere que la escritura de Marías utiliza los cuerpos femeninos como textos culturales 
que son interpretados y traducidos por los personajes masculinos. En lugar de investigar las razones tras el suicidio femenino, como es la propuesta inicial, autor y protagonista se convierten en traductores voyeristas de las inscripciones del suicidio en los cuerpos de las mujeres, deviniendo la novela una narrativa interesada de identidad masculina.

"Feminine and Failed Suicides in Spanish Cinema" de Anna Casas Aguilar y Claire Ranstrom argumenta que el fracaso de los suicidios es clave para entender dos películas: ¿Qué he hecho yo para merecer esto!! (1984) de Pedro Almodóvar y Costa Brava (Family Album) (1995) de Marta Balletbò-Coll. Sus protagonistas muestran cómo estos actos frustrados implican que el suicidio es más que una elección individual; surge de una serie de coyunturas sociológicas y en particular de género. En este sentido, se explora el conflictivo lugar de estas dos mujeres en relación con los modelos genéricos de la España de los años ochenta y noventa. Basándose en el trabajo de Katrina Jaworski, Gender-ing of Suicide (2010), que se opone a la tesis de Durkheim y ofrece una perspectiva de género y social, las autoras proponen que el suicidio fallido resulta esencial para la comprensión de la reescritura del mito de Edipo en ambas representaciones fílmicas.

Marina Bettaglio es la autora de "Cuando la madre (se) mata: suicidio, víctimas y victimarios en Secreta Penélope (2003) de Alicia Giménez Bartlett y Elena sabe (2007) de Claudia Piñeiro." Las dos novelas analizadas en este artículo corresponden a la vertiente policiaca y negra y tratan sobre el suicidio de dos mujeres: la amiga de la narradora, en el primer caso; y la hija de la protagonista, en el segundo. Los personajes de las dos novelas se ven confrontados con las circunstancias de las muertes y las responsabilidades sociales por las mismas, que emanan de conflictivas relaciones materno-filiales. A partir de las teorizaciones de Margaret Higonnet sobre el suicido, Bettaglio analiza los aspectos siniestros y castradores de la maternidad, así como las fuerzas discursivas que subyacen a la representación del suicidio. El examen de las representaciones de la muerte de las dos mujeres revela un malestar no solo individual sino también social dentro de la institución familiar.

Por último, parece oportuno señalar que la muerte por mano propia como tema de reflexión resulta de gran trascendencia en la actualidad, dados los cambios que se vienen operando en las mentalidades de este siglo en relación al rechazo de la carga moral negativa y a la consideración de la validez de este acto final, ideas que se incluyen en los debates sobre la eutanasia y la muerte voluntaria. En este sentido, además de profundizar en el análisis literario, este volumen representa un aporte al conjunto de la 
reflexión sobre un tema tan polémico y relevante en nuestras sociedades actuales.

Para concluir, damos las gracias a los autores que con entusiasmo respondieron a nuestra convocatoria y se abocaron a la escritura de artículos sobre un tema tan particular y complejo como es la relación entre suicidio y creatividad. Ellos colaboraron ampliamente en la finalización de este número, la redacción de sus artículos y las enmiendas subsecuentes. Asimismo, queremos agradecer el intenso trabajo de los evaluadores. Y finalmente, hacemos presente un reconocimiento especial a Rosalía Cornejo-Parriego, por su valioso respaldo en el proceso de edición de este volumen monográfico.

University of British Columbia / Mount Royal University

NOTAS

I Esta crisis de la figura autorial estaría vinculada con la muerte de Dios planteada por Nietzsche y la del arte, sugerida por Hegel y Marx (Pérez Parejo), así como con la idea de la desaparición del hombre en el siglo XIX y el nacimiento de un "superhombre" (Foucault 4I). Asimismo, en el área de las comunicaciones, en 1962, Umberto Eco hacía referencia a la crisis, para la cultura contemporánea, de un "cosmos ordenado" (Obra abierta 47).

2 Hay que aclarar que esta instancia autorial puede ser también relacionada con el lector, en tanto el conocimiento del suicidio por parte del autor es el que activa una lectura distinta de la obra.

3 No solo las sociedades cristianas condenaron el suicido. Por ejemplo, los judíos también estaban opuestos a la auto-eliminación, aunque encontraban justificaciones para el comportamiento suicida: la posibilidad de tortura, preservación de la castidad, bien del país, honor, etc. (Rosen 15 ).

4 De acuerdo a George Rosen, las penas aplicadas a los suicidas incluían la confiscación de tierra y/o bienes, y el castigo se extendía al cadáver: en Inglaterra, era enterrado en un cruce de caminos, para que el finado no pudiera descansar en paz (I4). En Francia, el cadáver era colgado por los pies y arrastrado por las calles, luego se le quemaba y arrojaba a la basura; en 1670 le Roi Soleil incorporó y oficializó en el código legal este tipo de prácticas, añadiendo la difamacion del nombre del suicidia y la pérdida de la nobleza si se trataba de un aristócrata (Alvarez, The Savage God 46-47).

5 Hay que señalar que las propuestas de Freud sobre el suicidio incluyen también esta idea de "melancolía". 
OBRAS CITADAS

Alvarez, A. "Literature in the Nineteenth and Twentieth Centuries". Ed. Seymour

Perlin. New York: Oxford UP, 1975. 3I-60.

-. The Savage God. A Study of Suicide. New York: Random House, 1972.

B RAND T, RICHARD. "The Morality and Rationality of Suicide". A Handbook for the

Study of Suicide. Ed. Seymur Perlin. New York: Oxford UP, I975. 6I-76.

B A RT H E S, R O L An D. El susurro del lenguaje. Barcelona: Paidós, I994.

camus, al B E r t. "The Myth of Sisyphus". On Suicide. Ed. John Miller. San Francisco:

Chronicle Books, I993. I07-116.

Dur k e im, e mile. Suicide. A Study in Sociology. New York: The Free Press, 1979.

EA G L TON, TERRy. Una introducción a la teoría literaria. México: Fondo de Cultura

Económica, 200I.

E C 0, u M B E R T 0. Lector in Fabula. Barcelona: Lumen, I98I.

-. Obra abierta. México: Editorial Artemisa, 1985.

Fo UCAUlt, Michel. “¿Qué es un autor?” El Seminario 12 de marzo de 20I8. S. pag.

Web.

GL OWIN SKI, MICHAEL. "Reading, Interpretation, Reception". New Literary History

II.I (I979): 75-82.

GR A F F, G ER ALD. Literature Against Itself. Chicago: The U of Chicago P, I979.

H I RSC H, E. D. Validity in Interpretation. New Haven y Londres: Yale UP, I975.

H U M E, D A VID. Essays on Suicide and the Immortality of the Soul by the Late David

Hume. Basil: Collection of English Classics/John Decker, I799.

ISER, W O LFAnG. "The Current Situation of Literary Theory: Key Concepts and the

Imaginary". New Literary History II.I (I979): I-20.

—. "El proceso de lectura: Enfoque fenomenólogico". Estética de la recepción. Comp.

José Antonio Mayoral. Madrid: Arco/Libros, I987. 215-243.

JAUSS, HANS ROBERT. "El lector como instancia de una nueva historia de la

literatura”. Estética de la recepción. Comp. José Antonio Mayoral. Madrid:

Arco/Libros, 1987. 59-85.

Lent tric Chia, frank. After the New Criticism. Chicago: The U of Chicago P, I980.

PÉREZ PAREJo, RAmón. "La crisis de la autoría”. Espéculo. Revista de Estudios

Literarios 26 (2004): S. pag. Web.

Pi Z A Rnik, aleja ndra. Semblanza. Comp. Frank Graziano. México: Fondo de

Cultura Económica, I992.

rosen, G E O R G E. "History". A Handbook for the Study of Suicide. Ed. Seymur Perlin.

New York: Oxford UP, 1975. 3-29.

Run C 0, MAR K. "Suicide and Creativity: The Case of Sylvia Plath". Death Studies 22.7

(1998): 637-657. 